\title{
Biblioteka kościelna w Borku Wielkopolskim
}

Kolekcja powstała prawdopodobnie w początach XVII wieku. Dokładna data nie jest dziś możliwa do ustalenia. Założycielem biblioteki był ksiądz Feliks Durewicz (urodzony w Śremie w 1576 - zmarł w 1646 r. w Borku Wielkopolskim), pierwszy proboszcz borecki w latach 1606-1646. Biblioteka mieściła się przy kościele Matki Boskiej na Zdzieżu, ${ }^{1}$ przeznaczona była dla potrzeb duchowieństwa parafii boreckiej, od 1655 r. dekanatu boreckiego.

W 1392 r. Zdzież uzyskał od Władysława Jagiełły prawa miejskie. Rozwijał się przez ponad dwadzieścia lat. Prawdopodobnie już wtedy istniały tam zaczątki kultu maryjnego. ${ }^{2}$ Pobliski Borek, należący podówczas do innego właściciela, był mniej znaczącą miejscowością. Przed 1423 r. straszliwy pożar doszczętnie zniszczył Zdzież, spłonął także kościół. Udało się ocalić wizerunek Matki Boskiej (przypuszczalnie rzeźbę), który przeniesiono czasowo do Borka. Korzystając z niepowodzenia konkurenta, właściciel Borka wystarał się w 1423 r. o przywilej lokacyjny dla swego miasta. Zdzież wprawdzie też odbudowano, ${ }^{3}$ ale nigdy już nie wydźwignął się do rangi samodzielnego miasta. W ciągu XV wieku, stał się przedmieściem Borka. Tak jest do dziś.

Zdzież stał się najważniejszą częścią Borka. Kult Matki Boskiej Pocieszenia, którego obiektem był i dotąd pozostaje XVI-wieczny obraz Madonny, wspaniale się tam rozwijał na przestrzeni wieków. Już w XVII wieku zjeżdzali tutaj pielgrzymi także spoza Polski.

Dzisiaj Sanktuarium Matki Bolskiej Boreckiej na Zadzieżu należy do największych w Wielkopolsce.

Biblioteka utworzona została zatem przy kościele zdzieskim, a nie przy mało znanym kościele św. Stanisława w Borku, mimo że za czasów Durewicza ten właśnie kościół był kościołem parafialnym. Wśród dowodów na miejsce przechowywania księgozbioru boreckiego sa zapiski proweniencyjne na ocalałych książkach oraz sprawozdania z wizytacji dekanatu boreckiego przez ówczesnych dostojników kościelnych w XVII i XVIII w., gdzie wyraźnie się określa: biblioteka przy kościele Matki Boskiej na Zdzieżu.

Ilość książek była różna w różnych latach. Nie da się tego dziś dokładnie 
ustalić. Można jedynie przypuszczać na podstawie późniejszych danych, że księgozbiór - przynajmniej za życia Durewicza - liczył ponad tysiąc woluminów. ${ }^{4}$ Składały się nań inkunabuły oraz druki z XVI i XVII w. Feliks Durewicz był człowiekiem wykształconym, miłośnikiem książek, które sprowadzał także z zagranicy. Wszystkie dotyczyły tematyki teologicznofilozoficznej.

Dzieje księgozbioru boreckiego są dziś możliwe do odtworzenia tylko we fragmentach. Przyjmuje się, iż powstał on na początku XVII w. i że jego twórca, a ściślej: założycielem biblioteki, był Feliks Durewicz. Na książkach podpisywał się z lacińska jako Duranius lub Durinius.

Najstarszy odnaleziony zapis proweniencyjny (z nazwiskiem Durewicza!) pochodzi z $1601 \mathrm{r}$. Daty w tej i innych notkach proweniencyjnych określaja moment nabycia książki. Można jednak podejrzewać, że do ok. $1606 \mathrm{r}$. (objęcie przez Durewicza probostwa) książki były po prostu własnościa owego księdza. Biblioteka została prawdopodobnie utworzona dopiero w tym roku. Jest niemal pewne,że Durewicz włączył wtedy do kolekcji część lub całość swoich prywatnych zbiorów.

Nie wiadomo, w jaki sposób wzbogacano później księgozbiór. Książki w większości były zapewne kupowane. Za jakie środki? Też nie wiadomo. Durewicz zarządzał biblioteką z racji swego urzędu, a po jego śmierci to samo czynili - lepiej lub gorzej - następni proboszczowie w Borku. $\mathrm{Za}$ Duraniusa przypuszczalnie istniały inwentarze, ale brak na to dowodów.

Po śmierci Durewicza, w latach 1646-1656, gdy proboszczem był Adam Budziecki (notki proweniencyjne $\mathrm{z}$ jego nazwiskiem znajdują się na wielu książkach), stan biblioteki był dobry. Budziecki również był bibliofilem, prywatnie bardzo dużo czytał, a z urzędu kupował nowe księgi do kolekcji. Nie wiadomo jednak ani ile ksiązek przybyło, ani z ilu cały zbiór się wówczas składał.

Po okresie "potopu" szwedzkiego zarówno biblioteka jak i miasto Borek podupadły, chociaż kościół zdzieski nie został splądrowany. Kolejni proboszczowie: Jan Trzeminski (zm. 1678) i Bartłomiej Korybski (zm. prawdop. 1703 lub 1704) biblioteka zbyt gorliwie sie nie zajmowali. W sprawozdaniu z wizytacji dekanatu boreckiego, dokonanej w 1684 r. przez archidiakona śremskiego, Jacka Ignacego Gnińskiego, jest wzmianka o tym, że biblioteka była zaniedbana, a książki rozproszone. Gniński polecił ustawić książki według treści, natomiast wypożyczone lub zabrane odzyskać. 
W 1707 r., w czasie wojny północnej, część księgozbioru boreckiego zrabował Mikołaj Płatonow, dowódca jednaego z rosyjskich oddziałów. Wybierał tylko ksiązki z pozłacanymi grzbietami, inne pozostawiając. Niestety, brak jest jakichkolwiek danych liczbowych.

W 1742 r., podczas kolejnej wizytacji Borka (dokonał jej Franciszek Woliński, archidiakon śremski), okazało się, że w kościele zdzieskim funkcjonowały już dwie biblioteki: jedna dla wszystkich księży, druga wyłącznie dla kapelanów św. Józefa. ${ }^{5}$ Kolegium siedmiu kapelanów św. Józefa (od reguły życia wspólnego nazwanych później księżmi komunistami) utworzono przy kościele zdzieskim w 1649 r., który z braku powołań rozwiązano w 1786 r. W 1742 r. księgozbiory zawierały wiele rzadkich książek. Żadna z bibliotek jednak nie miała katalogów.

Podział na dwie biblioteki przetrwał do 1778 r., a być może dłużej. Gdy w lipcu 1778 r. wizytował Borek Józef Rogalinski, koadiutor archidiakona śremskiego, biblioteki były jeszcze dwie, a ich księgozbiory liczyły łącznie ok. 1000 książek i zawierały wiele rzadkości bibliograficznych.

Po śmierci w 1803 roku Melchiora Pomorskiego, stanowisko proboszcza w Borku wakowało przez dziewięć lat. Dopiero w 1812 r. objął je Maciej Cichowicz, którego usunięto w $1825 \mathrm{r}$. Za jego czasów podupadły zarówno probostwo jak i biblioteka. Podobno dochodziło do tego, że księgozbiór był rozkradany. Znaczna część księgozbioru trafiła wtedy do Warszawskiego Towarzystwa Przyjaciól Nauk, którego bogatą bibliotekę zagrabili Rosjanie i przywieźli do Petersburga.

Tym niemniej pewna ilość książek pozostała w Borku. W $1835 \mathrm{r}$. postanowiono reaktywować i rozbudować bibliotekę. W Aktach Konsystorza Generalnego Arcybiskupa Poznańskiego, dotyczących wyżej wymienionej sprawy znajduje się $\mathrm{m}$. in. odpis statutu biblioteki. Paragraf 1 brzmi: "W kościele zdzieszewskim, w którym już od dawna założoną jest biblioteka kościelna, lokal jak najstosowniejszy na bibliotekę dekanalną obiera się". Natomiast paragraf 2 informuje m.in., że: "W bibliotece kościelnej w Zdzieszu znajduje się obecnie paręset książek (...)". Z innego punktu statutu wynika, że do nowo utworzonej biblioteki w Borku miano przewieźć ponad 70 ksiązek (wraz z szafami) z kościła w Mchach, miejscowości położonej niedaleko Borka. Zamiar ten chyba zrealizowano. W zachowanej do dziś części księgozbioru boreckiego jest 6 książek z notkami proweniencyjnymi świadczącymi o pochodzeniu tych woluminów z biblioteki mchowskiej.

Nadzór nad biblioteką miał sprawować ówczesny proboszcz Franciszek 
Wolniewicz, a po nim kolejni proboszczowie. W paragrafie 6 statutu czytamy m.in.: "(...) ksiądz Kwoliński, wikariusz w Borku, zobowiązuje się przy pomocy innych duchownych bibliotekę bezpłatnie uporządkować i wszystkie książi spisać (...)". Znaczyłoby to, iż w 1835 r. nie w pełni znano zawartość księgozbioru.

Nie są znane dalsze dzieje biblioteki boreckiej. Nie wiadomo, co działo się z księgozbiorem w pierwszej połowie XX w. i w czasie ostatniej wojny. Ocalałą część księgozbioru włączono do Biblioteki Archiwum Archidiecezjalnego w Poznaniu.

Księgozbiór borecki liczy obecnie 1 inkunabuł i 86 woluminów starych druków. Głównie są to druki z XVI i XVII w., nieliczne zaś z poczatku XVIII w., wszystkie o tematyce teologiczno-filozoficznej. Na większości książek widnieją rękopiśmienne notki proweniencyjne.

Zbiór nie był dotąd opracowany i nie posiada dokumentacji. Jedynym opracowanym elementem kolekcji jest inkunabuł:

Petrus de Alliaco: Quaestiones super libros Sententiarum.

Argentinae (Strassburg) 149014.4

(Typ. Iordani + Ge. Husner)

Przechowuje się go oddzielnie w dziale inkunabułów Archiwum.

Natomiast trzon kolekcji starych druków stanowią wydawnictwa obce. Oto kilka cennych przykładów:

- Origenis adamantii, eximii scripturarum interpretis opera quae quidem extant omia per des Erasmus Roterodamum (...) Basilea 1557.

- Annales ecclesiastici auctore Caesare Baronio sorano ex congregatione oratori S.R.E. presbytero cardinale (...) Tomus septimus. Romae ex Typographia Vaticana 1596.

- Evangelicarum dilucidatorum libri VIII in totidem euchyridii evangelicorum libros (...) Authore Vincentio Regio. Sumptibus Bernardi Gualteri 1615.

Wśród druków obcych są i platiniana:

- Annales ecclesiastici auctore Caesare Baronio sorano congregationis oratorii presbytero. Tomus secundus ab eodem recognitus et emendatus. Antverpiae ex Officina Platiniana 1591.

- Catena LXV. Patrum Graecorum in Sanctum Lucam quae quatuor simul evangelistarum introducit explicationem. Luce ac Latinitate donata, et ex aliis Patribustam Graecis quam Latinis suppleta, et annotationibus illustrata,à Balthasare Corderio Soc. Iesu Theologo. Antverpiae ex Officina Platiniana Balthasaris Moreti 1628. 
Nielicznie reprezentowane sa druki polskie:

- Pars aestiva concionum pro festivitatibus Christi, B.Virgins et Sanctorum (...). Auctore M.Simone Stanislao Makowski (...). Cracoviae, apud Haeredes et Successores Lucae Kupisz S.R.M. typograph. A.D. 1665.

- R.P. Gasparis Druzbicki e Societate Iesu in historiam passionis Domini Nostri Iesu Christi. Secundum quatuor evangelista stromata in lucem edita A.D. 1697. Calisii, typ. Col. Soc. Iesus.

- Electa divi augustini ecclesiae doctoris a celsissimo principe Casimiro Floriano duce in Klevvan Czartoryski (...) A.D. 1671 accurate collecta et perillustris ac reverendissimi Domini Domini Thomae Stanislai Niemierza. A.D. 1688 publicae luci exposita. In typ. Coll. Posnaniensis Soc. Iesu.

Na koniec interesujące polonicum zagraniczne

- D. Stanislai Hosii S.R.E. Tituli Sancti Clementis presbyteri (...) Opera omnia, quorum catalogum octava pagella reperies, opera haec nunc novissime ab ipso auctore dilingenter recognita: (...) D. doctoris Henrici Dunghaei canonici antverpiensis edita. Antverpiae in edibus Viduae et Haeredum Ioannis Stelsii 1571

Proweniencje odręczne:

1. Feliks Durewicz (1576-1646) - zw. z łac. Duraniusem lub Duriniusem.

- Inscriptus Catalog sub? Felicis Srzem 1601

- Librorum sum Cathalogo Faelicis Srzem Durewicz pleb. Bor. mpp 1608

- Ex cathalogo (...) Felicis Srzem Durinii plebani Borcens... 1616

- Inscriptus cathalogo librorum Felicis Srzem Durinii plebani Borcensis A.D. 1616 die ultima februarii

- Sum Felicis Durinii plebani Borcens. (...) 5? Juli 1617

- Sum Felicis Srzem Durinii plebani Borcen. 1618 Septem. 18 
- Sum ex (libris) Felicis Srzem Durinii par. Borcens. A.D. 161819 septembr.

- Sum Felicis Srzem Durinii plebani Borcen. 24 Aug. 1619?

- Sum Felicis Durinii A.D. 161923 septembr.

- Sum Felicis Srzem Durinii plebani Borcen. A.D. 1619 die 25 septembr.

- Felicis Duranii p. Bor. emptus (...) 24 julii A.D. 1636

- Felicis Duranii praepositi ecclesiae in Borek A.D. 1636 (25 lub 26) septembr.

- Felicis Duranii p. Bor. 30 januarii A.D. 1638

- Felicis Duranii p. Borcens. A.D. 1639 aprilis 17

-... ex libris Felicis (Srzem) plebani Borcens.

- Inscriptus cathalogo librorum Faelicis a Srzem

- Felicis Srzem Duranii praep. Borcens.

- Felicis Srzem (Duranii) pleb(ani) Borcens (...)

- Felicis Durinii plebani Borcens.

2. Kościół Matki Boskiej na Zdzieżu.

- Emptum cum Antiphonario pro ecclesiae BMV collegiata in Zdziesz A.D. 1696

- Ecclesiae BMV in Zdriesz, emptus A.D. 1701 die 1 maii

- Ecclesiae BMV in Zdziesz ad Borek 1708 
- Ecclesiae BMV in Zdziesz iuxta oppidum Borek novissime cessit ab infra scripto(rum) 1708

- Pro bibliotheca ecclesiae BMV in Zdziesz ad Borek 1708 (...)

- Ecclesiae BMV in Zdziesz iuxta oppidum Borek Diecenzis Posnaniensis 1714

- Nunc eccl. BMV in Zdziesz ad Borek 1714

- Ecclesiae BMV in Zdziesz iuxta Borek a preafate (...) donatus liber A. 1717

- Ex bibliotheca ecclesiae BMV Zdzieszensis

- Pro bibliotheca ecclesiae BMV in Zdziesz ad Borek

- Pro bibliotheca ecclesiae BMV in Zdziesz iuxta Borek

- Ecclesiae BMV in Zdziesz iuxta oppidum Borek

- Ecclesiae BMV in Zdziesz

- Ecclesiae BMV in Zdziesz ad Borek

- Ecclesiae BMV in Zdziesz ad oppidum Borek

- Ecclesiae Zdzieszensis ad Borek

- Ecclesiae Zdzieszensis penes oppidum Borek

- Ecclesiae BMV in Zdziesz penes Borek

- Ecclesiae et bibliotheca Zdzieszevien(sis) iuxta oppidum Borek

- Nunc eccl(esiae) Zdzieszoviens(is) ad Borek 
- Bibliotheca Borcensis Zdzieszeviensis

3. Kolegium kapelanów św. Józefa.

- Collegi Capellanorum S. Josephi in Zdziesz

- Collegi S. Josephi in Zdziesz

- Collegi Capellanorum S. Josephi ad eccl(esia)m BMV in Zdziesz

- E nunc (...) libr. Thomas Pauli mpp 1657

- Thomae Pauli Cap. S. Jos. in Zdziesz 1671

- A suprascripto emit Thomas Pauli Capel. S. Josephi 1694

- Ab in transcripto emit Thomas Pauli Capellanus S. Josephi 1694

- Ecclesiae in cuius sacraevallensis R(evere)ndi P. Thomae Pauli S. Josephi in Zdziesz 1708 (...)

- Ab infrascripto (..) ad primum possessorem Thomam Pauli (...) S. Josephi in Zdziesz

- Liber ex libris R(evere)ndi Stephani Słupczyński? C.S.I. (Coll. S. Iosephi?)

- Dono accepi et? R(everen)do Stephano Słupczyński? nunc R(everen)do Iosephi Stoiński Coll. S. Iosephi Capell.

4. Inne.

- Inscriptus (...) Posnaniersis Soc. Iesu A.D. 1618

- Ex catal. libri. Collegi Posnaniensis Soc. Iesu An. 1631 
- Inscriptu... catal. Coll. Posnan. Soc. Iesu

- Verus possessor libri huius Francisci Lubomski? ab Anno 1661

- Cessit in usque R.P. Francisci Lubomski (...) Coll(egia)ta Lascensis Can(oni)ci et Cone (Consiliarius?) 167316 octobris

- Stanislai Imielii? plebani Sierakoviensis Decani Ruralis Lvovecensis. Emptus 16 florenorum 15 gr. A.D. 163317 sept. Ecclesiae Cosminensis cessit

- Stanislai Francisci Borkowicz 1686

- Sumptu Adm( ... Barthol. Felicis Koribski Dec. ac Praecepti. Borcens. a 1704

Bartłomiej Korybski - proboszcz Borka w 1. 1678-1703 lub 1704; od $1684 \mathrm{r}$. również dziekan dekanatu boreckiego

- Ex libris bibliothecae decanalis neomestensis in (Mchy) 1802

- Adami Budziecki parochii iarocinensis (lub iaraczoviensis) Adam Budziecki - proboszcz Borka w latach 1646-1656

- R(everendissimus) P(ater) Matthaei Borzewski (...) in Zdziesz Mateusz Borzewski - cysters, opat lędzki, od 1599 r. właściciel Borka, który odkupił od Stanisława Bnińskiego, kalwinisty; zm. 1614

- Ex Benedicti Falecki praepos... Koscielniensis? (...) Professi Tyniecensis mpp

- Ex libris (...) Adm. Ach. Melchioris Fogliński? (...) Parochii Rado...? mpp

- W ofiarze dane do Biblioteki Dekanalnej kościoła zdzieszewskiego X. Fr. Kwoliński

Franciszek Kwoliński - wikariusz w Borku; w 1835 r. zajmował się porządkowaniem księgozbioru

- pieczątka owalna z treścia: Archiwum Archidiecezjalne Poznań 
Zrodła i bibliografia.

Visitatio

Archidiaconatus sremensis ab Ignatio Gniński archidiakono sremensi a. 1672-1685. Peracta.

AAP AV 17 (1684 r.)

Akta Konsystorza Generalnego Arcybiskupiego Poznańskiego. Tyczące się założenia biblioteki w dekanacie borkowskim $1835 \mathrm{r}$.

AAP KA 10546

Brandowski A.: Parafia borecka podcass napadu szwedzkiego od roku 1655-165'. - Poznań, 1878.

Brandowski A.: Hustoria kościolów zdzieskich. - Poznań, 1889.

lincyklopedia katolicka. - T. 2. - Lublin, 1976. - T. 4. - Lublin, 1983

Nowacki J.: Dzieje Archidiecezii Poznariskıej. T. 2. - Poznań, 1964.

Slownik pracowników ksiqzki polskiej - Łódż; Warszawa, 1972

Przypisy

1.

Slownik pracownikow ksiazki polskicj (Warszawa 1972. s 189 ) pod hasłem Durewicz Feliks mylnie podaje, ze biblioteka mieściła się przy kosciele sw. Stanısława w Borku Wlkp.

2.

Według tradycjı ustnej ok 1390 r. wydarzył sıę tu cud obıawıenia Matkı Boskıej, a woda z miejscowego źródła przywróciła wzrok ślepcowi.

3.

W $1428 \mathrm{r}$ był już gotowy nowy drewniany kosciół Rzeźba wrociła z Borka na 
poprzednie miejsce

4.

O sporych rozmiarach księgozbioru może świadczyc fakt, iż jeden $z$ introligatorów boreckich Maciej Pempa, (zm. 1649) na tyle się dorobit, że zapisał koscielnemu znaczny legat

\section{5}

Przypuszczalnie był to ciagle jeden księgozbiór, z którego częśc wydzielono do użytku kapelanów św. Józefa. 